\title{
ENSINO E PESQUISA: DESAFIOS E POSSIBILIDADES PARA DOCENTES UNIVERSITÁRIOS INICIANTES*
}

\author{
Beatriz Maria Boéssio Atrib Zanchet, \\ da Universidade Federal de Pelotas
}

\begin{abstract}
Resumo: Como docentes iniciantes, na carreira universitária, enfrentam os desafios da passagem de uma formação que privilegia a pesquisa para uma prática eminentemente de docência é o foco da discussão apresentada. A pesquisa utilizou para a coleta de dados entrevistas semiestruturadas com docentes iniciantes, mestres e/ ou doutores, que atuam em diferentes áreas do conhecimento e exercem a docência em diferentes universidades. A partir da análise dos dados foi interessante perceber que os docentes reconheceram, dentre outros aspectos, que a pesquisa ajuda-os a aprender a pensar e a observar as coisas sob outros ângulos. Isso acaba gerando outros conhecimentos e assim vão enfrentando os desafios requeridos para ensinar.

PalavRAs-Chave: Professores universitários iniciantes. Ensino superior. Ensino e pesquisa.
\end{abstract}

As políticas educacionais brasileiras definidas no panorama socioeconômico mundial enfatizaram elementos que gravitam ao redor da economia e do redimensionamento do capitalismo contemporâneo, da redefinição do papel do Estado, dos impactos das transformações tecnológicas, dentre outros. Nesse quadro, surge a emergência de uma força de trabalho que seja capaz de ficar atenta ao cenário mundial, pois novas qualificações vão sendo delineadas e exigidas para a vida em sociedade. Mais do que desempenhar funções cognitivas e estar em processo de aprendizagem permanente, solicita-se para a educação, um padrão de atitude que envolva a cooperação, a autonomia, a capacidade de comunicar-se e trabalhar em equipe.

\footnotetext{
* Artigo recebido em 01/08/2011 e aprovado em 04/10/2011.
} 
Os debates sobre a qualidade da educação assumiram o novo marco como referência. Evidenciada nos debates e agendas de diferentes segmentos da sociedade, a educação é alçada a um patamar estratégico de promoção e desenvolvimento de novas habilidades e competências para fazer frente ao mundo do trabalho. O discurso oriundo do mercado, assumido na educação, foi responsável por importantes transformações na estrutura curricular e na definição do papel dos professores, bem como nos mecanismos de gestão dos sistemas educativos. Nota-se, de forma bastante clara, nos documentos oficiais, a incorporação da terminologia empresarial ao mundo da educação.

O mesmo discurso coloca desafios à universidade, que, apesar de continuar a ser a instituição por excelência de conhecimentos científicos, começou a perder a hegemonia que tinha e foi se transformando, pouco a pouco, num alvo fácil de crítica social. Como explica Santos (2004, p. 39), "na última década começaram a alterar significativamente as relações entre conhecimento e sociedade e as alterações prometem ser profundas a ponto de transformarem as concepções que temos de conhecimento e de sociedade". O autor aponta que a comercialização do conhecimento científico é o lado mais visível dessas alterações, embora isso seja apenas a ponta do iceberg, pois as transformações em curso são de sentido contraditório e as implicações são múltiplas, inclusive de natureza epistemológica.

O conhecimento científico foi, ao longo do século XX, predominantemente disciplinar, o que gerou um processo de produção científica pouco relacionado às premências da sociedade. Nessa lógica, os pesquisadores, na maioria das vezes, são aqueles que definem os problemas científicos para os quais devem buscar solução, definindo sua relevância e estabelecendo o método e o ritmo da pesquisa. Para Santos (2004), esse é um conhecimento homogêneo na medida em que agentes participantes de sua produção têm em comum os mesmos objetivos de produção de conhecimento, têm a mesma formação e a mesma cultura científica e fazem-no segundo hierarquias organizacionais bem definidas. O conhecimento produzido na lógica desse processo provoca a distinção entre conhecimento científico e outros conhecimentos, e, consequentemente, faz distinção entre ciência e sociedade.

Entendemos que a organização universitária e o ethos universitário foram moldados por este modelo de conhecimento. Entretanto, as alterações ocorridas nas últimas décadas desestabilizaram os referenciais que prevaleciam para pensar o conhecimento e passaram a apontar para a emergência de outra lógica para a sua produção. Santos (2004, p. 41) designa essa transição por passagem do conhecimento universitário para o conhecimento pluriversitário. Explica o autor que o conhecimento pluriversitário é contextual na medida 
em que o princípio organizador da sua produção é a aplicação que lhe pode ser dada. Nessa perspectiva, aponta Santos que

como essa aplicação ocorre extramuros, a iniciativa da formulação dos problemas que se pretende resolver e a determinação dos critérios da relevância destes é o resultado de uma partilha entre pesquisadores e utilizadores. É um conhecimento transdisciplinar que, pela sua própria contextualização, obriga a um diálogo ou confronto com outros tipos de conhecimento, o que o torna internamente mais heterogêneo e mais adequado a ser produzido em sistemas abertos menos perenes e de organização menos rígida e hierárquica. (SANTOS, 2004, p. 41)

No entanto, é preciso estar atento, pois o conhecimento pluriversitário tem apresentado a sua concretização mais consistente nas parcerias universidade - indústria e, portanto, sob a forma de conhecimento mercantil.

Diante dessas transformações, observamos que a universidade fica exposta a exigências contrapostas, mas com o efeito convergente de desestabilizarem a sua institucionalidade atual. Segundo o autor, a instabilidade causada pelo impacto destas pressões contrapostas cria impasses, tornando evidente que as exigências de maiores mudanças vão frequentemente de par com as maiores resistências à mudança.

Percebe-se, assim, que a passagem do conhecimento universitário para o conhecimento pluriversitário é, portanto, um processo muito mais amplo que a mercantilização da universidade e do conhecimento por ela produzido.

Nessa perspectiva, o conhecimento não pode ser proposto como algo acabado, mas como produto determinado e situado dentro de relações sociais específicas e, ao mesmo tempo, dependente de determinada visão de mundo. As exigências sobre as universidades superaram sua capacidade de resposta, o financiamento público diminui, ficando cada vez mais dependente dos resultados, o conhecimento excede aos recursos e se cria uma grande demanda de toda ordem. Vale ressaltar, também, que a competitividade no mundo do trabalho vem abalando a organização acadêmica, ainda apegada às carreiras tradicionais. A organização interna dos currículos, baseada em competências bem definidas, dá lugar a novas propostas. Emergem discursos com ênfase na interdisciplinaridade, na flexibilização e em outros conceitos nessa direção que, até há pouco tempo, eram raros na educação superior. Esta condição colide com a trajetória de formação da maioria dos professores, porque se distancia de suas histórias. Também exige uma apropriação teórica que grande parte não possui, dificultando o entendimento de propostas que tentam atender esses discursos. Como a implementação das propostas 
depende do trabalho cotidiano do professor, infere-se que o sucesso ou fracasso do sistema escolar são de sua responsabilidade. Nesse sentido, a prática pedagógica dos professores precisa ser acompanhada e controlada, pois, na lógica administrativa, essas são as estratégias eficazes para reforçar sua responsabilização pelos resultados dos sistemas educacionais.

No Brasil, em relação à formação de professores universitários, a Lei de Diretrizes e Bases (1996) refere-se a uma "preparação" a ser desenvolvida nos Programas de Pós-Graduação strictu senso, de todas as áreas do conhecimento. Esses Programas, em geral, não focalizam sua atenção nos saberes da docência, privilegiando especialmente as habilidades de pesquisa, que é considerada um fundamental atributo da qualidade da educação superior. Os processos seletivos que envolvem concursos públicos avaliam o domínio do conhecimento específico do candidato para assumir o cargo de docente. Se os conhecimentos específicos são considerados principais, como afirma Barco (1999), "a demonstração das capacidades docentes fica restrita ao espaço de um simulacro: se 'dá' uma aula na audiência de alunos, ou se explica como se procederia com os alunos, dos quais se desconhecem as características, apelando-se, portanto, para sua abstração". A autora afirma ainda que o concurso aparece, assim, como "um rito de passagem" (p. 153), referindo-se à transformação de qualquer profissional em professor a partir desse processo seletivo.

O peso das produções científicas e dos títulos acadêmicos assumiu maior expressão. Na maioria dos casos, os títulos de mestre e doutor constituem condição de inscrição. Esse cenário explicita que o perfil de pesquisador passa a se constituir no vetor da qualidade da educação superior e, portanto, da condição docente. Vai se consagrando o perfil de um professor que se distancia da representação histórica do quem sabe fazer, sabe ensinar, passando para a equação que pressupõe que quem sabe pesquisar, sabe ensinar (CUNHA, 2010).

Tem-se hoje um corpo docente ingressante constituído na sua maioria de jovens doutores que realizaram uma formação acadêmica com sucesso e imediatamente ingressam na carreira docente. Se indagados sobre o motivo desta escolha, mencionam, sobretudo, que escolhem a universidade por ser o lugar de fazer pesquisa. Percebemos que esse perfil de docente também corresponde a uma concepção de qualidade para a educação superior, aquela que destaca a investigação e a produção do conhecimento como eixos principais de sua condição acadêmica.

Assim, a tensão apresentada indica que, na expectativa da sociedade, o papel da universidade é ensinar bem aos jovens a serem competentes e 
competitivos profissionalmente, assegurando-lhes as ferramentas básicas para serem incluídos no mundo do trabalho. A pesquisa se estabelece como pano de fundo dessa expectativa, porque qualifica e prestigia a formação profissional requerida, sendo reconhecida como requisito fundante da profissão universitária. Cada professor está preparado para abordar os temas que pesquisa, num recorte de sua especialidade. Entretanto, na dimensão do ensino, os saberes próprios da profissão docente Ihe são alheios. Sem desconsiderar a importância da formação investigativa na trajetória de jovens doutores, é difícil imaginar que eles possam fazer rupturas epistemológicas e correr riscos de desenvolver uma pedagogia que certamente se afasta de suas trajetórias estudantis.

Como, então, trabalhar com a tensão que envolve ensino e pesquisa no âmbito dos currículos universitários e nas práticas de ensinar e aprender que deveriam implementar? É possível afirmar que a formação em pesquisa é dispensável na educação superior? Entender como os professores iniciantes na carreira universitária percebem os saberes da pesquisa podendo ou não contribuir para suas ações pedagógicas e para o ensino que desenvolvem tornou-se objeto da pesquisa aqui apresentada.

\section{O PERCURSO INVESTIGATIVO: APROXIMAÇÕES COM O CAMPO EMPÍRICO}

Várias são as questões que nos mobilizaram e deram rumo à pesquisa. Dentre elas citamos: Como os processos de ensino e pesquisa vão se constituindo para o docente iniciante? Como percebem, sendo pesquisadores habilitados, a relação entre ensino e pesquisa? Como os saberes da pesquisa os ajudam a ser professores? Que saberes valorizam mais na docência universitária? Como aprendem a fazer mediações entre ensino e pesquisa?

O primeiro delineamento do campo empírico se deu por meio da definição das Universidades que poderiam participar da pesquisa. Para tal, consideramos como critérios: localização geográfica em relação à atuação dos pesquisadores participantes do grupo (RS e PR) e dependência administrativa (públicas e privadas). A partir desses critérios, buscamos nas Universidades Federal de Pelotas (UFPel), Universidade do Vale do Rio dos Sinos (UNISINOS), Universidade Federal do Pampa (UNIPAMPA) e Universidade Federal do Paraná (UFPr) - setor Litoral - a indicação de professores que poderiam constituir a amostra através do contato com os coordenadores dos diferentes Cursos dessas Instituições de Ensino Superior (IES). Após apresentarmos a pesquisa, solicitamos aos coordenadores que nos fornecessem os nomes dos professores iniciantes - com até cinco anos na carreira docente universitária - e oriundos de diferentes profissões. Ao recebermos a listagem com os nomes 
dos professores que atendiam esses critérios, fizemos um mapeamento inicial dos docentes e de suas respectivas áreas de atuação. No segundo momento, conversamos com os professores indicados para saber a sua disponibilidade em participar da pesquisa através de uma entrevista semiestruturada.

Constituímos uma amostra, a partir da disponibilidade dos docentes, com 27 professores ${ }^{1}$ que atuam em diferentes Cursos.

A entrevista semiestruturada é composta por vários eixos temáticos, como por exemplo: motivos/razões para ingressar na docência universitária (como se tornou professor universitário); experiências iniciais na profissão docente; formas de apoio encontradas na IES ou no Departamento ou no Curso; relação com os estudantes; lugar de formação do professor universitário; saberes específicos para a docência e relação entre as atividades de pesquisa e atividades da docência. As questões foram organizadas de tal forma que nos permitisse ter um panorama geral sobre as ideias de cada respondente em relação a esses tópicos. Além disso, essas questões foram elaboradas levando em consideração os estudos e a trajetória realizada pelo grupo, como também as pesquisas da área, tais como as de Cunha (1998; 2003; 2005; 2006); Pimenta (1999), Barnett (2008); Mayor Ruiz (2009); Zabalza (2004), Marcelo Garcia (1999), entre outros. A análise dos dados considerou os princípios da análise de conteúdo, pois esse enfoque constitui-se em um conjunto de técnicas de análise de comunicação "visando obter, por procedimentos sistemáticos e objetivos de descrição do conteúdo das mensagens, indicadores que permitam a inferência de conhecimentos relativos às condições de produção/ recepção destas mensagens" (Bardin,1979, p. 42).

O ENSINO E A FORMAÇÃO PARA A PESQUISA: O QUE EXPRESSARAM OS PROFESSORES

Há um pressuposto inquestionável de que a pesquisa qualifica o ensino e sobre ele há uma concordância implícita que todos ratificamos. Mas será que essa relação se faz de forma tão linear? Sempre que há pesquisa haverá ensino de qualidade? Os saberes que sustentam a pesquisa serão suficientes para a realização de práticas pedagógicas significativas?

Essas questões são instigantes para analisar o fenômeno da educação superior na contemporaneidade e se tornam mais intensas quando se analisa o caso dos jovens doutores que acorrem à carreira docente na expectativa de encontrar um espaço de profissionalização. Estimulados a realizar seus cursos de mestrado e doutorado, aprenderam a trajetória da pesquisa e, em geral, aprofundam um tema de estudo verticalmente, num processo progressivo de especialização. Quando se incorporam à educação superior nesses tempos de interiorização e massificação, descobrem que deles se exige uma gama 
maior de saberes, em especial para o exercício da docência. Percebendo a docência como ação complexa, terão de dominar o conhecimento disciplinar nas suas relações horizontais, em diálogo com outros campos que se articulam curricularmente, ultrapassando a visão linear do conhecimento no qual se aprofundaram na sua verticalidade.

Assim, percebe-se que essa situação torna-se preocupante na universidade e é acrescida das tensões estabelecidas entre a pesquisa e o ensino, entre a produção acadêmica e a gestão ou entre a pesquisa básica e a extensão. Nesse cenário, há a aposta de que a formação pedagógica do docente universitário seja incentivada para estimular os professores a construírem as bases de sua identidade profissional docente, contemplando a possibilidade do desenvolvimento de um trabalho conjunto para a construção das abordagens pedagógicas que precisam constituir.

Ao serem questionados sobre o ensino que desenvolvem, suas respostas apontaram, como condição importante para o exercício da docência no ensino superior, a formação de sua base profissional mesmo que ela não seja voltada para o ensino. Disse-nos um entrevistado que "eu vejo que se você conhece o assunto que vai trabalhar, uma coisa é você ter uma base e ter o conhecimento sobre aquele assunto que você vai dar aula, não adianta você querer dar aula de uma coisa que você não preparou, que você não tem convívio. $O$ saber está ligado à prática do professor e à pesquisa que ele desenvolveu" (B2).

Os entrevistados mostraram uma preocupação relacionada à formação pedagógica, pois nos seus cursos de mestrado e/ou doutorado não tiveram oportunidades de discutir o ensino. Afirmaram que esses cursos estão muito voltados para a formação do pesquisador e pouca ou nenhuma preocupação é vislumbrada com a finalidade da preparação do professor para enfrentar os desafios da sala de aula. Explicaram que o curso de graduação foi balizado na perspectiva técnica e posteriormente a pós- graduação foi alicerçada na investigação de problemas muito específicos; logo, esses aspectos limitaram significativamente sua prática pedagógica, como relata um professor: "não sei absolutamente nada de didática, nunca discuti um autor. Tudo que aprendi é porque observei alguém fazendo, é porque troco figurinhas com os alunos para tentar achar o caminho" (A1).

Os professores explicaram que a docência é um exercício que pode ser aprimorado, mesmo que no início ele seja repleto de dificuldades. Argumentam que, se o professor gosta do que está fazendo e tem interesse na docência, vai melhorando e superando as dificuldades encontradas. Afirmaram que ter o domínio consistente do conteúdo é condição mínima 
para o bom desempenho de sua função. Os docentes universitários, segundo Pimenta e Anastasiou (2008, p. 198), desenvolvem "habilidades referentes ao método de pesquisa que conta com especificidades bem diferentes do método de ensino".

Perguntados sobre a necessidade de saberes específicos para o ensino, as respostas apontaram para a importância do conhecimento da relação ensino-aprendizagem, das relações pedagógicas para tentarem interagir da melhor forma com os estudantes. A compreensão dessas relações pode ajudá-los a ensinar melhor os conteúdos e, talvez, ajudálos a desenvolver melhor o processo de avaliação com seus alunos. Os professores salientaram, vale destacar, que seria importante contemplar um aprofundamento nas questões da formação específica da área aliando-as às da formação pedagógica e às que correspondem à pesquisa. Mesmo que os professores tenham mencionado essa condição, é necessário ressaltar que seus cursos de graduação os habilitaram para o exercício de uma profissão que não é a docência.

Nossos entrevistados alertaram que os concursos para professores universitários não exigem essa formação. Um deles disse que "a formação, no caso de mestre ou doutor, ela tem uma lacuna na área pedagógica, no ensino, e até eu mesmo acho que há muitos critérios, por exemplo, num concurso, em que um dos principais aspectos é a publicação de artigos científicos, mas isso não é garantia de que o professor, sendo um grande pesquisador, vai ser um bom professor" (B3).

Torna-se importante retomar o dilema entre a formação para a docência e a formação para a pesquisa que é explicitado por Zabalza (2004), pois, para esse autor, nas universidades existe a orientação de desenvolver atividades tanto de ensino como de pesquisa. Entretanto, a cultura universitária tem atribuído um maior status acadêmico à pesquisa e lhe dado prioridade. Segundo o autor,

o que normalmente é avaliado nos concursos de ingresso e promoção são os méritos das pesquisas; o que os professores e seus departamentos tendem a priorizar por causa dos efeitos econômicos e do status são as atividades de pesquisa; o destino prioritário dos investimentos para formação do pessoal acadêmico, em geral, é orientado principalmente para a formação em pesquisa (muitas vezes, é administrado pelas pró-reitorias de pesquisa) e assim sucessivamente. (ZABALZA, 2004, p. 154)

É comum, na universidade, a concepção de que para ser um bom professor universitário, o mais importante é ser um bom pesquisador, pois este possui uma visão mais sistemática e um maior conhecimento do campo 
científico. Essa condição eleva a atividade de pesquisa a um grau intelectual superior à atividade de ensino e parece fazer parte da cultura docente. Sobre isso disse-nos um entrevistado que "um bom professor não necessariamente é um bom pesquisador e vice-versa, embora tenhamos situações em que ambos os casos ocorram. Mas eu acho que não existe uma correlação direta entre isto" (A3).

No entanto, a cultura docente não é tributária apenas da experiência historicamente acumulada nos padrões de atuação desse grupo profissional; ela é influenciada pelas pressões e expectativas externas, pelos requerimentos situacionais dos sujeitos envolvidos. Essa característica põe em evidência a articulação entre a cultura docente e o processo social mais amplo, isto é, sua dimensão ideológica e política e, por isso mesmo, não neutra. Podemos dizer que a cultura docente é um fator importante a considerar em todo projeto que se pretende implantar na universidade em geral, e nos cursos, em particular. Um professor reafirma essa condição quando diz que "hoje em dia todo mundo quer ser pesquisador, é difícil tu encontrar um professor que entre na universidade que queira ser extencionista, por exemplo, são raros, porque a gente tem na verdade proposições macro que sinalizam para isso" (para a pesquisa) (B3).

Podemos observar que a universidade teve de atribuir um maior status acadêmico à pesquisa até transformá-la no componente básico da identidade e do reconhecimento do docente universitário. Além disso, fez com que o ensino se transformasse em uma atividade secundária dos docentes. Muitas vezes, na universidade, aceita-se que a pesquisa constitua um grau de desenvolvimento intelectual superior, uma oportunidade para ver os assuntos pesquisados de forma mais rigorosa e sistemática, um maior conhecimento dos temas que transitam nos campos científicos. Em contrapartida, essa argumentação é fraca se analisada sob a ótica do ensino. Disse-nos um professor que, em alguns casos, "as pesquisas abastecem de certa forma um pouco o que estou passando hoje para os alunos ... eu estou conseguindo, de certa forma, explorar alguns dos resultados, das coisas que a gente vem trabalhando, com meus alunos dentro da sala de aula" (A3). Outro entrevistado afirmou que "a pesquisa alimenta a prática docente com indagações e produção de conhecimento, a extensão também. Procuro sempre trabalhar de forma integrada. Conhecer a realidade através de pesquisa, desenvolvendo o senso crítico dos alunos no ensino e trabalhando na realidade através da extensão" (B1,5). Os docentes iniciantes entrevistados explicaram que a especialidade e o aprofundamento de um tema específico de sua área poderá "atrapalhar" sua condição de professor. Nesse sentido, 
um deles afirmou que "meu doutorado foi muito específico e me atrapalhou, porque a minha pesquisa é muito direcionada, é com uma família, a Botânica, e agora eu dou aula de tudo. Então muita coisa eu tive que voltar a estudar, retomar para entrar numa sala de aula" (A1).

As afirmações dos entrevistados nos remetem ao que Zabalza (2004, p. 11) explica sobre a docência, pois, para o autor, "conhecer bem a própria disciplina é uma condição fundamental, mas não é o suficiente". E complementa explicando que o trabalho docente envolve vários tipos de conhecimentos e competências que necessitam de uma preparação específica. O autor diz, também, que a capacidade intelectual do docente e a forma como abordará os conteúdos são muito distintas de como o especialista o faz. Esta é uma maneira de se aproximar dos conteúdos ou das atividades profissionais pensando em estratégias para fazer com que os alunos aprendam. Essa posição é ratificada na expressão de um docente quando disse que "um dos desafios é sempre estar me perguntando se o conteúdo e a metodologia que a gente está utilizando, a didática em sala de aula está atendendo a questão do aluno até para o mercado de trabalho, tanto é que é uma questão que eu estou me perguntando e que talvez seja o meu desafio de doutorado, trabalhar a formação do assistente social, então esse é o meu desafio. Eu não diria que é uma dificuldade, eu vejo mais como um desafio, o que eu estou ministrando em sala de aula é realidade para a profissão?" (A4).

Quando questionamos os docentes sobre a construção de saberes para a docência a partir do desenvolvimento de pesquisas, alguns deles afirmaram que é importante a decisão sobre o que podem e devem pesquisar. Um entrevistado disse que "pode mesmo que da sala de aula, em função da própria interação com os alunos saia uma proposta, uma ideia de pesquisar e isso aí tem que ser uma coisa muito harmoniosa, não pode ter proposições entre pesquisa e ensino paralelas e distantes. Eu acho que a gente tem que tentar aproximá-las [...] é bastante possível sim" (B3).

É interessante salientar o que um docente disse a respeito da pesquisa: "eu particularmente gosto muito da pesquisa aplicada, não gosto de situações que são meramente contribuições científicas, pois essa aplicação prática é inviável. Eu gosto de tentar interagir numa situação que a gente possa aplicar ela realmente na prática. Então se a gente conseguir levantar ou executar experimentos, pesquisas com esse enfoque, eu acho que naturalmente elas vão para a sala de aula depois, porque no momento que tu tens essas informações, tu vais poder usá-las no contexto da tua disciplina e então ter essa troca com os alunos, interagir" (B3). Outro professor enfatizou: "para mim, o professor é, ele não deixa de ser, ele é pesquisador, ele é docente, 
e ele é o que vai fazer extensão, o que vai passar conhecimento ou para o aluno ou para a sociedade", e reiterou afirmando que "para ser pesquisador, ser um bom pesquisador, ele necessitaria de um pouco de docência, porque a meu ver é mais importante a pergunta do que a resposta e de que forma tu desenvolves uma boa pergunta para realizar uma boa pesquisa? É na prática docente, mentes jovens, dúvidas novas, perguntas boas" (B2).

Nessa perspectiva, entendemos as especiais exigências intelectuais mencionadas por Brown e Atkins (apud Zabalza, 2004) ao afirmarem que

além de conhecer os conteúdos os docentes devem ser capazes de: analisar e resolver problemas; analisar um tópico até detalhá-lo e torná-lo compreensível; observar qual é a melhor maneira de se aproximar dos conteúdos e de abordá-los nas circunstâncias atuais; selecionar as estratégias metodológicas adequadas e os recursos que maior impacto possam ter como facilitadores da aprendizagem; organizar as ideias, a informação e as tarefas para os estudantes. (p. 111)

Como em qualquer outra profissão, é importante uma educação continuada que, no caso da docência, envolve a dimensão da pesquisa e a dimensão do ensino. A docência será uma atividade profissional na medida em que essa condição se materializar. A atividade de ensino exige a ressignificação dos conhecimentos teóricos em contextos de práticas que são peculiares e localizadas. Os professores universitários enquanto profissionais, sejam iniciantes ou mais experientes, precisam assumir uma atitude de reflexão constante sobre suas práticas, teorizando os fundamentos de suas decisões pedagógicas.

\section{CONSIDERAÇÕES COMPLEMENTARES}

Algumas vezes, nas universidades, não há coincidência entre conteúdos de pesquisa e conteúdos da docência. No entanto, foi interessante perceber que os docentes reconheceram que a pesquisa faz, muitas vezes, com que o pesquisador desenvolva atividades de professor, pois ela ajuda-os a aprender a pensar e a observar as coisas sob outros ângulos, o que acaba gerando outros conhecimentos. Mesmo que nossos interlocutores tenham mencionado que durante seus cursos de mestrado e/ou doutorado aprenderam metodologia para fazer pesquisa e não aprenderam metodologia de ensino, entendemos que expressaram, nas suas falas, preocupação com uma formação que os ajude a enfrentar os desafios da docência, pois de qualquer forma, as funções de docência e de pesquisa precisam de formação. 
A incorporação ao mundo da pesquisa, na maior parte das vezes, ocorre em um contexto mais específico e regulado. Zabalza (2004, p. 155) argumenta que as competências e qualidades profissionais para o ensino e para a pesquisa são diferentes.

Torna-se importante, no contexto da formação dos docentes iniciantes na carreira universitária, refletir sobre sua formação pedagógica, além de buscar compreender os processos que esses docentes vivenciam para construir saberes para o ensino.

Concordamos com Pimenta e Anastasiou (2008) quando explicam que a docência na universidade"configura-se como um processo contínuo de construção da identidade docente e tem por base os saberes da experiência, construídos no exercício profissional mediante o ensino dos saberes das áreas do conhecimento". As autoras afirmam também que para que a identidade de professor se configure, é necessário que o docente ponha-se em "condições de proceder à análise crítica desses saberes da experiência construídos nas práticas, confrontando-os e ampliando-os com base no campo teórico da educação, uma identidade epistemológica decorrente de seus saberes científicos e os de ensinar" (p. 88). Além disso, salientamos que a tarefa fundamental do professor universitário iniciante, durante seus primeiros anos de docência, deveria ser a aprendizagem, focando seu pensamento e seu comportamento nas demandas do ensino. Ou seja, é importante aprender a linguagem da prática do ensino. Nas palavras de Howey (apud, MAYOR RUIZ, 2001), encontramos o que consideramos ser necessário nessa etapa de iniciação à docência:

La tarea fundamental del profesor principiante durante sus primeros años de docencia debe ser el aprendizaje, dirigido a enfocar su pensamiento y sus comportamientos hacia las demandas de la enseñanza, es decir, aprender el lenguaje de la practica. (p. 3)

Nessa perspectiva, acreditamos que os docentes iniciantes talvez deveriam dedicar-se, nos primeiros anos da carreira, a desempenhar funções que os ajudassem a aprender e que destinassem mais tempo para a sua formação como professor.

TEACHING AND RESEARCH: CHALLENGES AND POSSIBILITIES FOR BEGINNER UNIVERSITY PROFESSORS

ABSTRACT: How professors at the start of a university career face the challenges of moving from an education process focused on research to one that mainly involves teaching practice is the theme of this discussion. Semi-structured interviews with beginner 
professors, Masters and PhDs, working in different scientific fields and lecturing in different universities were used to collect data. From an analysis of the data it was interesting to notice that teachers recognized that, among other aspects, research helps them learn how to think and observe from other perspectives, thus providing them with knowledge to face the challenges of teaching.

KEYWORDS: Beginner university professors. Higher education. Teaching and research.

\section{NOTA}

1. A amostra ficou assim distribuída: 9 (nove) professores da UFPel, 6 (seis) professores da UNIPAMPA, 6 (seis) professores da UNISINOS e 6 (seis) da UFPr - setor Litoral. Os professores serão identificados pelas letras $A$ - se for professora e B - se for professor seguido de um número que indica o tempo de docência universitária, com a finalidade de preservarmos sua identidade.

\section{REFERÊNCIAS}

BARDIN, L. Análise do discurso. Lisboa. Edições 70, 1979.

BARCO de SURGUI, Suzana. Formação do docente universitário: mas quem é ele? In: VEIGA, Ilma Passos; CUNHA, Maria Isabel da (Org.). Desmistificando a profissionalização do magistério. Campinas, Papirus, 1999.

BARNETT, Ronald (ed.) Para una transformación de la universidad. Nuevas relaciones entre investigación, saber y docencia. Barcelona, Editorial Octaedro, 2008.

CUNHA, Maria Isabel da. O professor universitário na transição dos paradigmas. Araraquara/SP, JM Editora, 1998.

CUNHA, Maria Isabel da. O bom professor e sua prática. 15. ed. Campinas, SP: Papirus, 2003.

CUNHA, Maria Isabel da (Org). Formatos avaliativos e concepção de docência. Campinas, SP: Autores Associados, 2005.

Pedagogia Universitária: energias emancipatórias em tempos neoliberais. Araraquara, SP: Junqueira \& Marin, 2006.

. Qualidade do ensino de graduação: relação entre pesquisa, ensino e desenvolvimento profissional docente. Projeto de pesquisa, 2010.

MARCELO GARCIA, Carlos. Formação de professores. Para uma mudança educativa. Porto, Porto Editora, 1999.

PIMENTA, Selma (Org). Saberes pedagógicos e atividade docente. São Paulo: Cortez, 1999.

PIMENTA, S.; ANASTASIOU, Léa das Graças C. Docência no Ensino Superior. 3 ed. São Paulo: Cortez, 2008. 
MAYOR RUIZ, Cristina. Los condiciones profesionales del profesorado universitario. Um estúdio com profesores principiantes y com experiência. Revista Granada, v. 8, p. 27-51, 2001.

MAYOR RUIZ, Cristina. El desafio de los profesores principiantes universitarios ante su formación. In: MARCELO GARCIA, Carlos. El profesorado principiante: inserción a la docencia. Barcelona, Octaedro, 2009. p. 177- 210.

SANTOS, Boaventura de S. A universidade no século XXI: para uma reforma democrática e emancipatória da universidade. São Paulo: Cortez, 2004.

ZABALZA, Miguel A. O ensino universitário: seu cenário e seus protagonistas. Porto Alegre: Artmed, 2004.

Beatriz Maria Boéssio Atrib Zanchet é Doutora em Educação e professora do PPGE da UFPel. Orienta alunos doutorandos, mestrandos e bolsistas de iniciação científica. Os estudos e pesquisas têm como foco o ensino superior e a formação de professores, bem como seus saberes e práticas. 